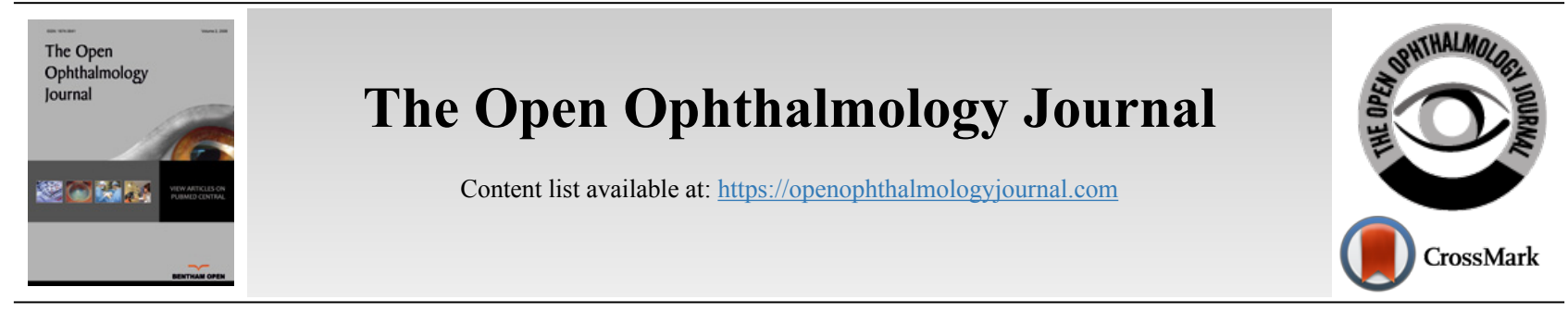

RESEARCH ARTICLE

\title{
Effect of Internal Limiting Membrane Peeling on Macular Structure and Metamorphopsia Scores in Idiopathic Epiretinal Membrane Surgery
}

\author{
Tekin Aydin ${ }^{1}$, Suleyman Gokhan $\operatorname{Kerci}^{2} \mathbb{D}$, Omer Karti, ${ }^{3, *}$, Mehmet Ozgur Zengin ${ }^{4}$ and Tuncay Kusbeci ${ }^{2}(\mathbb{D}$ \\ ${ }^{1}$ Department of Ophthalmology, Dr.Ersin Arslan Training and Research Hospital, Gaziantep, Turkey \\ ${ }^{2}$ Department of Ophthalmology, Bozyaka Training and Research Hospital, Izmir, Turkey \\ ${ }^{3}$ Department of Ophthalmology, Izmir Democracy University, Izmir, Turkey \\ ${ }^{4}$ Department of Ophthalmology, İmir Katip Çelebi University, İmir, Turkey
}

\begin{abstract}
:
Backgrounds and Objective:

Pars Plana Vitrectomy (PPV) and epiretinal membrane (ERM) peeling is the standard surgical procedure of ERM surgery. However, the effect of adding Internal Limiting Membrane (ILM) peeling to the standard surgery on macular function and structure remains still controversial. This study was aimed at investigating the effect of ILM peeling on the macular function and structure in idiopathic ERM surgery.

Method:

Thirty-six eyes of 34 patients were evaluated in this prospective study. The patients were divided into two groups (ILM peeling and non-ILM peeling group). While the removal of ERM was undergone alone in 19 eyes, it was combined with ILM peeling in 17 eyes. Metamorphopsia scores Vertical Metamorphopsia (VM) and Horizontal Metamorphopsia (HM), were measured at preoperative and 4 months postoperatively.

Results:

There was a statistically significant decrease in metamorphopsia (VM and HM) scores in both groups after the surgery. However, no statistically significant difference was found between the two groups in terms of reduction in VM scores and HM scores after surgery.

Conclusion:

Our study indicated that ILM peeling combined with ERM did not affect metamorphopsia scores.
\end{abstract}

Keywords: Epiretinal membrane, Internal limiting membrane, Metamorphopsia, Muller cells, Pars plana vitrectomy, Vitreous.

\begin{tabular}{|l|l|l|l|}
\hline Article History & Received: November 21, 2019 & Revised: January 18, 2020 & Accepted: January 29, 2020
\end{tabular}

\section{INTRODUCTION}

Idiopathic Epiretinal Membrane (ERM) is characterized by avascular fibrocellular proliferation located at the central macula on the inner Limiting Membrane (ILM) [1]. While the estimated prevalence is $2 \%$ in the population aged less than 60 years, this prevalence is up to $12-20 \%$ in population beyond age 70 [2]. ERM can cause metamorphosia, macropsia, micropsia and monocular diplopia as well as decrease in visual acuity. Pars Plana Vitrectomy (PPV) and removal of the membrane are performed as standard surgical procedure in ERM surgery. The rate of improvement in visual acuity after

* Address correspondence to this author at the Department of Ophthalmology, İzmir Democracy University, İzmir, Turkey; Tel: +905055985685;

E-mail: kartiomer@gmail.com successful surgery has been reported to be $90 \%$ [3 - 6]. However, ERM recurrence occurs in $10 \%$ of patients if the ERM peeling is performed alone and approximately $2 \%$ of these patients require re-treatment [3]. Therefore, ILM peeling has been recently added to standard surgery to reduce the recurrence [7]. Since ILM is a basal lamina formed by the footplates of Muller cells, peeling of this membrane can cause functional and morphological damage to the retina. Therefore, current role of ILM peeling in ERM surgery is still controversial. While some studies reported that ILM peeling did not have a negative effect on the macula $[7,8]$, the others reported impaired electrophysiological responses $[9,10]$

In this study, we aimed to evaluate the effect of ILM peeling combined with ERM surgery on macular volume, 
visual acuity and metamorphosia scores.

\section{MATERIALS AND METHODS}

Our study was conducted prospectively between January 2018 and June 2018 at the Bozyaka Training and Research Hospital. The patients were included in the study in accordance with the ethical standards of the Declaration of Helsinki after the approval of the local ethics committee (Bozyaka Training and Research Hospital, date: 17.01.2018, reference no: [5]). The study included 36 eyes of 34 patients with idiopathic ERM. ERM peeling were performed alone in 19 patients and combined with ILM peeling in the remaining 17 patients. The types of surgical procedures to be undergone to the patients were determined randomly. Both patients and investigators were masked to the intervention. Only the surgeon was aware of the randomization result. The inclusion criteria for ERM surgery were defined according to the patients' visual acuity and the presence of metamorphosia. When the visual acuity was less than 20/30 regardless of metamorphosis, the surgery was recommended. However, in patients whose visual acuity was better than $20 / 30$ at diagnosis, the surgery was recommended in the presence of moderate or severe metamorphosis. Patients with secondary ERM due to retinal vascular diseases, ocular inflammation, blunt or penetrating trauma, previous ocular surgery, laser photocoagulation, and cryotherapy were excluded. Patients with previous vitrectomy, additional macular disease and grade 2 or more advanced nuclear cataracts were also excluded. The demographic data of all patients were recorded. Detailed ophthalmological examination including Best-Corrected Visual Acuity (BCVA), slit-lamp exam, intraocular pressure measurement, and dilated fundus examination was performed before and 4 months after the surgery. BCVA was measured by Snellen chart and converted to the logarithm of the minimum angle of resolution ( $\log$ MAR). Fundus examination was performed with a 78- or 90- diopter lens and indirect ophthalmoscopy. Metamorphopsia scores vertical and horizontal metamorphopsia scores (VM and $\mathrm{HM}$ ) were measured at a distance of $30 \mathrm{~cm}$ using the MCHARTS system (Inami, Japan) after correcting the refractive error with spectacles for near vision. Measurement of macular volume including Retinal Nerve Fiber layer (RNFL), Ganglion Cell Layer (GCL), Inner Plexiform Layer (IPL), Inner Nuclear Layer (INL), Outer Plexiform Layer (OPL) and Outer Nuclear Layer (ONL) were measured automatically with Spectral Domain Optical Coherence Tomography (SD-OCT) (Heidelberg Engineering, Germany). All OCT measurements were performed with the same OCT device by the same technician. In addition, same OCT scanning protocol was applied to all patients during each visit. A standard three-port PPV was performed in all patients by the same surgeon (S.G.K.) using a 23 gauge system. Phacoemulsification and foldable intraocular lens implantation were performed simultaneously if the patients were phakic. After core vitrectomy, posterior hyaloid membrane was removed. Following this procedure, trypan blue $0.06 \%$ (TB) was used to stain the ERM, and then ERM was removed from the retinal surface by tangential forces using microforceps. After ERM peeling, TB was injected in the vitreous cavity again to stain the ILM. While ILM was removed with the help of microforceps in ILM-peeling group, TB was aspirated without ILM removal in non-ILM peeling group. Finally, sulfur hexafluoride $20 \%$ (SF6) was given in all cases as an internal tamponade and the sclerotomies were closed with an applicator.

Statistical analysis was performed using SPSS 19.0 for Windows (SPSS, Inc.; Chicago, USA) package program. Kolmogorov-Smirnov and Shaphiro-Wilk tests were used to normality test for continuous variables. Descriptive values are defined as the number (n), percentage (\%), mean, median, standard deviation (SD). Pearson chi-square, Yates corrected chi-square and Fisher tests were used to compare categorical variables. While parametric tests (paired sample t test and independent $t$ test) were used for normally distributed data, nonparametric tests (Wilcoxon test, Mann-Whitney $U$ test) were used for non-normally distributed data. The relationship between the variables was evaluated with Pearson Correlation Test. The level of statistical significance was accepted as $p<$ 0.05 .

\section{RESULTS}

Thirty-six eyes of 34 patients were included in the study. The mean ages of the ILM peeling group ( 9 male, 8 female) and non-ILM peeling group ( 9 male, 10 female) were $67.47 \pm$ 5.99 and $67.68 \pm 6.23$, respectively. There was no statistically significant difference between the two groups in terms of demographic characteristics Table 1. A comparison of BCVA (log MAR) and metamorphopsia scores (M-charts) between both groups are presented in Table $\mathbf{2}$. There was a statistically significant decrease in metamorphopsia scores (HM and VM) in both groups after the surgery. Also, a significant visual improvement was observed in both groups postoperatively when compared to preoperative values. However, no statistically significant difference was found between two groups in terms of BCVA and metamorphopsia scores (HM and $\mathrm{VM}$ ) before and after surgery. A comparison of BCVA (log MAR) and metamorphopsia scores (M-charts) between two groups are shown in Table 3 . In the non-ILM peeling group, there was a statistically significant decrease in total macular, RNFL, GHL, IPL and OPL volumes, but a significant increase in the ONL volume. In the ILM peeling group, there was a statistically significant decrease in the total macular, RNFL, IPL and OPL volumes, but there was a statistically significant increase in ONL volumes. When compared to retinal volumes between surgical groups, there was a significant difference between the groups in terms of GHL volume, GHL volume was significantly higher in the non-ILM peeling group than ILM peeling group before surgery. However, no statistically significant difference was found in other retinal layers volumes between the two groups Table 4 . There was a negative correlation between preoperative metamorphopsia scores (VM and HM) and postoperative VM score changes $(\triangle \mathrm{VM})$ in both groups. A similar correlation was also observed in postoperative HM score changes $(\Delta \mathrm{HM})$ Table 5.

\section{DISCUSSION}

ERM is a fibrocellular membrane formed on the retinal surface by fibroblasts, macrophages, glial cells, and myofibroblasts [1]. PVD-induced ILM breaks occur in almost 
all of the patients with ERM and glial cells are proliferated after migrating to the retinal surface from the breaks. Due to the fibrocellular formation in the ERM, tangential pulling forces occur on the retina and these forces may cause wrinkles and distortions. As a result, visual acuity decreases and metamorphopsia occurs [11]. PPV and ERM peeling have been performed as a standard surgical procedure in ERM surgery since the 1970s. However, recent studies have suggested that ILM peeling should be added to the standard treatment because it reduces ERM relapse [12]. Many studies have been suggested that ILM peeling may reduce ERM recurrence $[7,8]$. In a study by Park et al. [7], while recurrence rate was found $21 \%$ in non-ILM peeling group, there was no recurrence in ILM peeling group [7].

Table 1. Patients Demographics.

\begin{tabular}{|c|c|c|}
\hline & p & non-ILM peeling group \\
\cline { 2 - 4 } & ILM-peeling group & $67,68 \pm 6,23$ \\
Mean \pm SD & $67,47 \pm 5,99$ & $68(54-80)$ \\
Median (range,min-max) & $68(60-80)$ & $0,917 *$ \\
& & $9(47,4)$ \\
Gender & $9(52,9)$ & $10(52,6)$ \\
Male [n (\%)] & $8(47,1)$ & $1,000^{* *}$ \\
\end{tabular}

Abbreviations: ILM, internal limiting membrane; n, number of patients; SD, standard deviation. ${ }^{*}$ Student $\mathrm{t}$ test, ${ }^{* *}$ Yates-corrected chi-square test.

Table 2. Comparison of BCVA (logMAR) and Metamorphopsia Scores (M-CHARTS) Before and After Surgery in ILM Peeling and Non-ILM Peeling Groups.

\begin{tabular}{|c|c|c|c|c|}
\hline & \multicolumn{3}{|c|}{ ILM peeling group Non-ILM peeling group } & \multirow[t]{2}{*}{ p1 p2 } \\
\hline & Mean \pm SD & Median (min-max) & & \\
\hline $\begin{array}{l}\text { BCVA (logMAR) } \\
\text { Preoperative } \\
\text { Postoperative }\end{array}$ & $\begin{array}{l}0,41 \pm 0,19 \\
0,20 \pm 0,15\end{array}$ & 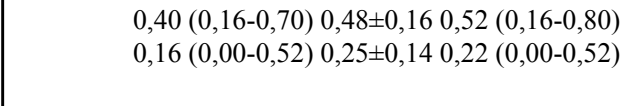 & & \\
\hline $\begin{array}{l}\text { VM score } \\
\text { Preoperative } \\
\text { Postoperative }\end{array}$ & $\begin{array}{l}0,47 \pm 0,27 \\
0,28 \pm 0,15\end{array}$ & $\begin{array}{l}0,40(0,2-1,1) \\
0,43 \pm 0,280,40(0,0-1,3) \\
0,20(0,0-0,7) 0,22 \pm 0,150,20(0,0-0,5)\end{array}$ & & $1 * *$ \\
\hline $\begin{array}{l}\text { HM score } \\
\text { Preoperative } \\
\text { Postoperative }\end{array}$ & $\begin{array}{l}0,49 \pm 0,28 \\
0,21 \pm 0,14\end{array}$ & $\begin{array}{l}0,40(0,0-1,0) 0,59 \pm 0,380,50(0,2-1,5) \\
0,20(0,0-0,4) 0,21 \pm 0,240,20(0,0-0,8)\end{array}$ & & $01 * *$ \\
\hline
\end{tabular}

Abbreviations: ILM, Internal Limiting Membrane; ERM, epiretinal membrane; BVCA, best corrected visual acuity; LogMAR, logarithmic minimum angle of resolution; HM, horizontal metamorphopsia; VM, vertical metamorphopsia; min, minimum, max, maximum. *Paired sample t test, **Wilcoxon test; p1, ILM peeling group (before vs. after surgery); 2 , non-ILM peeling group (before vs. after surgery).

Table 3. Comparison of BCVA (logMAR) and Metamorphopsia scores (M-charts) between both groups.

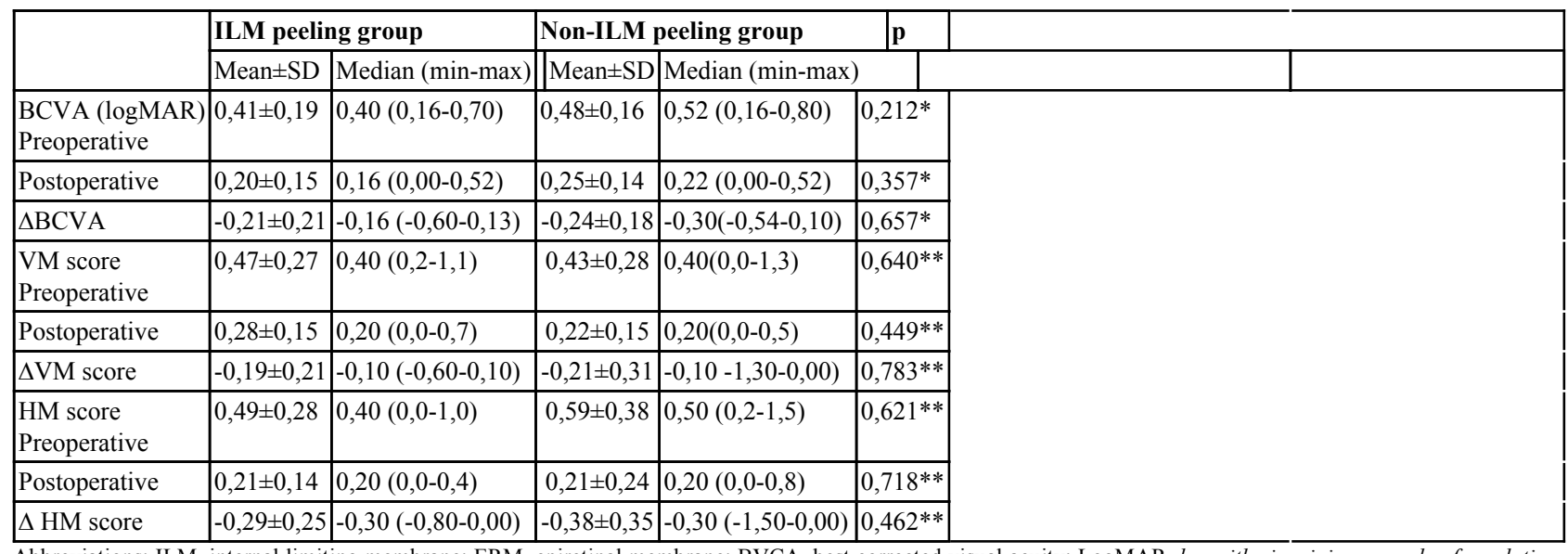

Abbreviations: ILM, internal limiting membrane; ERM, epiretinal membrane; BVCA, best corrected visual acuity; LogMAR, logarithmic minimum angle of resolution; $\triangle \mathrm{BCVA}$, changes in BCVA; $V M$, vertical metamorphopsia; $\triangle \mathrm{VM}$ score; changes in VM score; HM, horizontal metamorphopsia; $\Delta \mathrm{HM}$ score, changes in HM score; min, minimum; max, maximum. *Student $\mathrm{t}$ test, **Mann Whitney $\mathrm{U}$ test. 
Table 4. Comparison of Retinal Volume $\left(\mathrm{mm}^{3}\right)$ Values Before and After Surgery in ILM Peeling Group and Non-ILM Peeling Group.

\begin{tabular}{|c|c|c|c|c|}
\hline & \multicolumn{3}{|c|}{ ILM peeling group Non-ILM peeling group } & \multirow[t]{2}{*}{ p1 p2 p3 } \\
\hline & Mean \pm SD & Median (min-max) Mean \pm SD & Median (min-max) & \\
\hline $\begin{array}{l}\text { TMV } \\
\text { Preoperative } \\
\text { Postoperative }\end{array}$ & $\begin{array}{l}10,25 \pm 0,82 \\
9,47 \pm 0,57\end{array}$ & $\begin{array}{l}10,47(8,59-11,26) 10,15 \pm 0,76 \\
9,59(8,21-10,39) 9,61 \pm 0,88\end{array}$ & $\begin{array}{l}10,17(9,19-11,94) \\
9,42(8,19-11,46)\end{array}$ & $\begin{array}{l}<\mathbf{0 , 0 0 1} * *<\mathbf{0 , 0 0 1} * * 0,701^{\#} \\
0,584^{\#}\end{array}$ \\
\hline \begin{tabular}{|l|} 
RNFL volume \\
Preoperative \\
Postoperative
\end{tabular} & $\begin{array}{l}1,66 \pm 0,43 \\
1,05 \pm 0,21\end{array}$ & 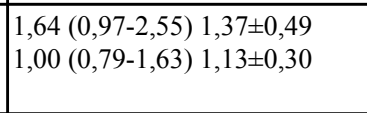 & \begin{tabular}{|l|}
$1,34(0,48-2,25)$ \\
$1,09(0,79-1,75)$
\end{tabular} & $\begin{array}{l}<\mathbf{0 , 0 0 1} * \mathbf{0 , 0 4 8} * * 0,072^{*} \\
0,646^{*}\end{array}$ \\
\hline $\begin{array}{l}\text { GCL volume } \\
\text { Preoperative } \\
\text { Postoperative }\end{array}$ & $\begin{array}{l}1,24 \pm 0,19 \\
1,08 \pm 0,13\end{array}$ & $\begin{array}{l}1,20(1,02-1,82) 1,37 \pm 0,24 \\
1,11(0,80-1,36) 1,14 \pm 0,14\end{array}$ & $\begin{array}{l}1,30(0,94-1,82) \\
1,15(0,81-1,35)\end{array}$ & $\begin{array}{l}0,722^{*}<\mathbf{0 , 0 0 1} * * \mathbf{0 , 0 3 8} \\
0,262^{*}\end{array}$ \\
\hline \begin{tabular}{|l|} 
IPL volume \\
Preoperative \\
Postoperative
\end{tabular} & $\begin{array}{l}1,10 \pm 0,10 \\
0,91 \pm 0,08\end{array}$ & $\begin{array}{l}1,08(0,94-1,30) 1,17 \pm 0,16 \\
0,91(0,77-1,07) 0,96 \pm 0,13\end{array}$ & $\begin{array}{l}1,20(0,87-1,56) \\
0,92(0,77-1,18)\end{array}$ & $\begin{array}{l}<\mathbf{0 , 0 0 1} * *<\mathbf{0 , 0 0 1} * * 0,104^{*} \\
0,197^{\#}\end{array}$ \\
\hline $\begin{array}{l}\text { INL volume } \\
\text { Preoperative } \\
\text { Postoperative }\end{array}$ & $\begin{array}{l}1,23 \pm 0,14 \\
1,23 \pm 0,12\end{array}$ & $\begin{array}{l}1,22(1,00-1,45) 1,21 \pm 0,11 \\
1,23(1,00-1,44) 1,22 \pm 0,15\end{array}$ & $\begin{array}{l}1,22(1,01-1,43) \\
1,20(1,01-1,57)\end{array}$ & $\begin{array}{l}0,815^{* *} 0,708^{* *} 0,701^{\#} \\
0,727^{*}\end{array}$ \\
\hline \begin{tabular}{|l|} 
OPL volume \\
Preoperative \\
Postoperative
\end{tabular} & $\begin{array}{l}0,94 \pm 0,10 \\
0,88 \pm 0,09\end{array}$ & $\begin{array}{l}0,92(0,76-1,15) 0,98 \pm 0,10 \\
0,86(0,73-1,11) 0,88 \pm 0,07\end{array}$ & $\begin{array}{l}0,98(0,80-1,22) \\
0,86(0,73-1,02)\end{array}$ & $\begin{array}{l}\mathbf{0 , 0 1 9 * *} \mathbf{0 , 0 0 1 * *} 0,150^{*} \\
0,926^{\#}\end{array}$ \\
\hline \begin{tabular}{|l|} 
ONL volume \\
Preoperative \\
Postoperative
\end{tabular} & $\begin{array}{l}1,87 \pm 0,23 \\
2,08 \pm 0,30\end{array}$ & 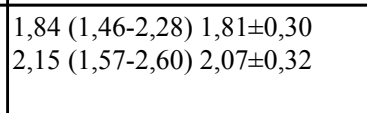 & $\begin{array}{l}1,85(1,37-2,46) \\
2,10(1,60-2,69)\end{array}$ & $\begin{array}{l}\mathbf{0 , 0 0 3} * *<\mathbf{0 , 0 0 1} * * 0,518^{\#} \\
0,879^{\#}\end{array}$ \\
\hline
\end{tabular}

Abbreviations: ILM, Internal Limiting Membrane; ERM, epiretinal membrane; TMV, total macular volume; RNFL, retinal nerve fiber layer; GCL, ganglion cell layer; IPL, inner plexiform layer; INL, inner nuclear layer; OPL, outher plexiform layer; ONL, outher nuclear layer; SD, standard deviation; min, minumum; max, maximum. *Wilcoxon test, **Paired sample t test, ${ }^{\#}$ Student $\mathrm{t}$ test, ${ }^{*}$ Mann Whitney U test. p1, ILM peeling group (before $v s .$. after surgery); p2, non-ILM peeling group (before $v s$. after surgery); p3, ILM peeling group $v$ s.. non-ILM peeling group.

Table 5. Correlation relationship between preoperative metamorphopsia scores and postoperative metamorphopsia changes in both groups.

\begin{tabular}{|l|l|c|c|c|c|}
\hline \multirow{2}{*}{} & \multicolumn{2}{|c|}{} & \multicolumn{2}{l|}{ ILM peeling group } & \multicolumn{2}{l|}{ Non-ILM peeling group } \\
\cline { 3 - 6 } & & $\Delta$ VM score & $\Delta$ HM score & $\Delta$ VM score & $\Delta$ HM score \\
\hline \multirow{2}{*}{ VM score (preoperative) } & $\mathbf{r}$ & $-0,832$ & $-0,609$ & $-0,869$ & $-0,659$ \\
\cline { 2 - 6 } & $\mathbf{p}$ & 0,000 & 0,010 & 0,000 & 0,002 \\
\hline \multirow{2}{*}{ HM score (preoperative) } & $\mathbf{r}$ & $-0,700$ & $-0,872$ & $-0,585$ & $-0,793$ \\
\cline { 2 - 6 } & $\mathbf{p}$ & 0,002 & 0,000 & 0,009 & 0,000 \\
\hline
\end{tabular}

Abbreviations: ILM, internal limiting membrane; ERM, epiretinal membrane; VM, vertical metamorphopsia; HM, horizontal metamorphopsia; $\Delta$ VM score, changes in VM score; $\Delta$ HM score, changes in HM score; $r$, correlation coefficient; $p$, significant value.

In an electron microscope examination conducted by Gandorfer et al. [13], the authors examined pathological data on the ERM removal with and without ILM peeling. They suggested that simple ERM removal resulted in sufficient separation of fibrocellular tissue in one-third of patients. In the remaining two-thirds of the patients, the vitreous cortex splits (vitreoschisis) and leaving an average of $20 \%$ of the total cell count behind on the ILM. Due to the proliferation capability of the cells that caused ERM recurrence, the authors suggested that ILM peeling should be added to ERM surgery. Due to the increasing rate of ILM peeling in ERM surgery, the functional and morphological effects of ILM peeling on the macula have been started to investigate. Since ILM consists of Muller cell footplates that act as a skeleton in the retina and are responsible for signal transduction, the peeling of this membrane may cause damage to Muller cells. While some studies $[7,8]$ in the literature reported that ILM peeling did not have a negative effect on the macula, the others stated that electrophysiological responses and visual field were impaired, but visual acuity was not affected $[9,10]$.

The most common complication of ERM surgery is cataract formation occurring in $60 \%$ of the patients. Therefore, most surgeons prefer the simultaneous cataract and ERM surgery $[14,15]$. Many studies have shown that there is no difference in visual outcomes between consecutive and combined surgeries performed in ERM surgery [16]. In a study, it was reported that combined surgery reduced the expenses and the required time interval to achieve final visual acuity [17]. Based on the results of these studies, we performed combined surgery in all phakic cases included in our study. Thus, we believe that we prevent the negative effect of cataract formation on test parameters [18].

The effect of ILM peeling on visual acuity still remains unclear [7, 8, 10, 19 - 25]. Several studies indicated that ILM peeling did not affect the BCVA after the ERM surgery $[7,8$, 
10, 19 - 22, 24, 25] Bovey et al. [26] reported that ILM peeling had a positive effect on visual outcomes. In a recent study by Tranos P et al. [27], the authors reported that ILM peeling did not affect the visual outcomes. In a recent meta-analysis study, visual acuity was found better in the ILM peeling group 18 months after the surgery, although it was worse during the first year [28]. In our study, a statistically significant increase in visual acuity was observed in both surgical groups after the surgery, but no statistically significant difference was found between the two groups in accordance with the literature.

Many studies have emphasized that structural macular changes occurred following the ERM surgery. One of the studies indicated that foveal thickness and macular volume decreased rapidly after ERM surgery [29]. However, there are few studies evaluating the thickness and volume of the retinal layers separately. Won JY et al. [30], stated that there was a significant decrease in the thickness and volume of inner retinal layers after ILM peeling group. Lee et al. [31] reported that RNFL thickness was decreased in ERM patients at 12 months after surgery. Some studies indicated a decrease in RNFL at 3 months after ILM peeling and then the decrease was found more evident in the following months $[32,33]$.

In an immunohistochemical study conducted by Kenawy $\mathrm{N}$ et al. [34], ILM specimens obtained during the vitrectomy were examined by light microscopy. The authors stated that removal of the ILM was more difficult in ERM surgery than in MH surgery. The percentage of glial and/or neuronal cells detected on the retinal surface of the ILM was found lower in the MH group (32\%) than ERM group (65\%) [34]. The percentages were attributed to fibrosis which was formed under ILM in ERM patients and the authors suggested that ILM peeling might cause RNFL loss. In our study, there was a statistically significant decrease in RNFL volumes after surgery in both surgery groups. However, there was no statistically significant difference between the two groups. Therefore, we considered that the decrease in RNFL volume might result from the disappearing of retinal traction which caused swelling of RNFL rather than RNFL loss.

Recent studies have reported that ILM peeling may cause deterioration of Muller cell orientation, decrease in retinal sensitivity and b-wave changes in electroretinography [35, 36]. In a study conducted by Deltour JB et al. [37], the authors investigated the microperimetric consequences of ILM peeling in idiopathic ERM surgery. They reported that ILM peeling did not affect the visual acuity after surgery but increased the development of deeper microscotomas. In recent studies, some anatomical damages such as separation of retinal nerve fibers and pitting of the inner retinal layers have been reported [38, 39]. In a randomized controlled trial, although there was no significant difference in visual acuity in the ILM peeling group compared with non-ILM peeling group, lower retinal sensitivity and higher rate of microscotoma were found in microperimetric measurements [40]. Based on these results, it is considered that the minimal mechanical damage to the retina resulted from ILM peeling is subclinical.

Vital Dyes which are organic molecules containing chromophores can selectively and reliably stain intraocular tissues. Various vital dyes including TB, indocyanine green
(ICG), infracyanine Green (IfCG), Triamcinolone Acetonide (TA), and Brilliant Blue G (BBG) have been defined for vitreoretinal surgery in the literature. While ICG, IfCG, and BBG selectively stain ILM, TB stains ERM [41]. Staining of ILM with TB remains controversial. Although some surgeons reported that ILM did not stain with TB $[42,43]$, others showed that TB stained both ILM and ERM adequately allowing complete removal. They suggested that it might be a better alternative for staining ILM and ERM [44,45]. Similarly, in our study, we observed that $0.06 \%$ TB enabled the identification of ILM during the surgical procedure.

Gas tamponade is not routinely used in a standard ERM surgery unless a peripheral retinal tear occurs [46 - 48]. However; Emrani et al. [49] reported the positive effects of the gas tamponade on the morphological and functional results in ERM surgery. They reported better visual outcomes and less central retinal thickness in patients receiving gas tamponade. The authors suggested that this improvement was due to the flattening and reducing effects of SF6 on retinal folds. In our clinical practice, we routinely use SF6 in ERM surgery. The main reasons why we use this tamponade are to reduce retinal folds and additional vitreoretinal traction, and thus to help flatten the retina. In addition, we believe that gas tamponade may reduce the risk of postoperative hemorrhage and may be effective in stabilizing postoperative intraocular pressure by preventing leakage from sutureless sclerotomy.

This study has two main limitations. One of them is a relatively small number of patients and the other is a short follow-up period. Besides limitations, one of the strongest aspects of our study is that pre- and post-operative quantitative measurements of metamorphopsia scores were performed by using M-CHART. Thus, as in previous studies, we tried to find out whether ILM peeling had a negative effect on the retinal function. To the best of our knowledge, there is no casecontrolled study investigating the effect of ILM peeling on metamorphopsia scores in the literature. In this respect, our study is the first clinical trial assessing this topic. In a study conducted by Tachibana $\mathrm{T}$ et al. [50], a significant improvement was found in HM scores after ILM peeling, but no similar improvement in VM scores and this result was attributed to the horizontal displacement of the macula due to ILM peeling [51]. In our study, there was a statistically significant decrease in VM and HM scores after ERM surgery in both groups, but no statistically significant difference was found between the groups. In light of our findings, it can be considered that ILM peeling can cause minimal damage to the retinal structure, but no significant effect on functional response in the clinical practice.

In a recent study conducted by Kinoshita $\mathrm{T}$ et al. [52] who measured pre- and post-operative metamorphopsia scores using M-CHARTS, the authors stated that the pre-operative metamorphopsia scores were a prognostic factor for postoperative metamorphopsia scores. In another study by the same group, pre-operative VM and HM scores were detected to be prognostic factors for the postoperative VM and HM scores [53]. As a result of these studies; the authors suggest that ERM surgery should be performed before a significant decrease in visual acuity and an increase of metamorphopsia severity. 
Similar to Kinoshita et al.'s study, we found a significant correlation between pre- and post-operative VM and HM scores in both groups. Based on our data, we consider that the pre-operative metamorphopsia score is a prognostic factor for the post-operative metamorphopsia scores.

\section{CONCLUSION}

In conclusion, because of the mechanical damage of macula induced by ILM peeling, further deterioration may occur in the Muller cells and inner retinal layer. As a result of this damage, retina microperimetric and electrophysiological responses may be impaired. In this study, we, however, did not observe any negative effect of ILM peeling on visual acuity and metamorphopsia scores. Therefore, we believe that the ILM peeling, which is shown to reduce the ERM recurrence, may be added to standard surgery. The findings in our study should be supported by further clinical trials.

\section{LIST OF ABBREVIATIONS}

$$
\begin{aligned}
& \text { PPV = Pars Plana Vitrectomy } \\
& \text { ERM = Epiretinal Membrane } \\
& \text { ILM = Internal Limiting Membrane } \\
& \text { VM = Vertical metamorphopsia } \\
& \text { HM = Horizontal Metamorphopsia } \\
& \text { BCVA = Best-Corrected Visual Acuity } \\
& \log \text { MAR }=\text { Logarithm of the Minimum Angle of Resolution } \\
& \text { RNFL = Retinal Nerve Fiber layer } \\
& \text { GCL = Ganglion Cell Layer } \\
& \text { IPL = Inner Plexiform Layer } \\
& \text { INL = Inner Nuclear Layer } \\
& \text { OPL = Outer Plexiform Layer } \\
& \text { ONL = Outer Nuclear Layer } \\
& \text { SD-OCT }=\text { Spectral Domain Optical Coherence Tomography } \\
& \text { SF6 = Sulfur Hexafluoride } \\
& \text { n } \quad=\text { Number } \\
& \text { SD } \quad=\text { Standard Deviation } \\
& \Delta \mathbf{V M}=\mathrm{VM} \text { score changes } \\
& \Delta \mathbf{H M}=\mathrm{HM} \text { score changes } \\
& \text { TB = Trypan Blue } \\
& \text { ICG = Indocyanine Green } \\
& \text { IfCG; = Infracyanine Green } \\
& \text { TA }=\text { Triamcinolone Acetonide } \\
& \text { BBG = Brilliant Blue G }
\end{aligned}
$$

\section{ETHICS APPROVAL AND CONSENT TO PARTI- CIPATE}

The study was approved by Bozyaka Training and Research Hospital, Izmir, Turkey under approval number 5.

\section{HUMAN AND ANIMAL RIGHTS}

No animals were used in this research. All human research procedures followed were in accordance with the ethical standards of the committee responsible for human experimentation (institutional and national), and with the Helsinki Declaration of 1975, as revised in 2013.

\section{CONSENT FOR PUBLICATION}

An informed written consent was obtained from all the patients when they were enrolled.

\section{AVAILABILITY OF DATA AND MATERIALS}

Not applicable.

\section{FUNDING}

None.

\section{CONFLICT OF INTEREST}

The authors declare no conflict of interest, financial or otherwise.

\section{ACKNOWLEDGEMENTS}

Declared none.

\section{REFERENCES}

[1] Smiddy WE, Maguire AM, Green WR, et al. Idiopathic epiretinal membranes. Ultrastructural characteristics and clinicopathologic correlation. Ophthalmology 1989; 96(6): 811-20.

[http://dx.doi.org/10.1016/S0161-6420(89)32811-9] [PMID: 2740079]

[2] Mitchell P, Smith W, Chey T, Wang JJ, Chang A. Prevalence and associations of epiretinal membranes. The Blue Mountains Eye Study, Australia. Ophthalmology 1997; 104(6): 1033-40.

[http://dx.doi.org/10.1016/S0161-6420(97)30190-0] [PMID: 9186446]

[3] Grewing R, Mester U. Results of surgery for epiretinal membranes and their recurrences. Br J Ophthalmol 1996; 80(4): 323-6. [http://dx.doi.org/10.1136/bjo.80.4.323] [PMID: 8703883]

[4] Margherio RR, Cox MS Jr, Trese MT, Murphy PL, Johnson J, Minor LA. Removal of epimacular membranes. Ophthalmology 1985; 92(8): 1075-83.

[http://dx.doi.org/10.1016/S0161-6420(85)33902-7] [PMID: 4047601]

[5] Poliner LS, Olk RJ, Grand MG, Escoffery RF, Okun E, Boniuk I. Surgical management of premacular fibroplasia. Arch Ophthalmol 1988; 106(6): 761-4

[http://dx.doi.org/10.1001/archopht.1988.01060130831033] [PMID: 3370001]

[6] Shimada H, Nakashizuka H, Hattori T, Mori R, Mizutani Y, Yuzawa M. Double staining with brilliant blue $G$ and double peeling for epiretinal membranes. Ophthalmology 2009; 116(7): 1370-6. [http://dx.doi.org/10.1016/j.ophtha.2009.01.024] [PMID: 19427701]

[7] Park DW, Dugel PU, Garda J, et al. Macular pucker removal with and without internal limiting membrane peeling: Pilot study. Ophthalmology 2003; 110(1): 62-4.

[http://dx.doi.org/10.1016/S0161-6420(02)01440-9] [PMID: 12511347]

[8] Kwok AKh, Lai TY, Yuen KS. Epiretinal membrane surgery with or without internal limiting membrane peeling. Clin Exp Ophthalmol 2005; 33(4): 379-85.

[http://dx.doi.org/10.1111/j.1442-9071.2005.01015.x] [PMID: 16033350]

[9] Tari SR, Vidne-Hay O, Greenstein VC, Barile GR, Hood DC, Chang S. Functional and structural measurements for the assessment of internal limiting membrane peeling in idiopathic macular pucker. Retina 2007; 27(5): 567-72.

[http://dx.doi.org/10.1097/IAE.0b013e31802ea53d]

[PMID: 17558317]

[10] Lim JW, Cho JH, Kim HK. Assessment of macular function by multifocal electroretinography following epiretinal membrane surgery with internal limiting membrane peeling. Clin Ophthalmol 2010; 4: 689-94.

[http://dx.doi.org/10.2147/OPTH.S12042] [PMID: 20689783]

[11] Snead DR, James S, Snead MP. Pathological changes in the vitreoretinal junction 1: Epiretinal membrane formation. Eye (Lond) 
2008; 22(10): 1310-7.

[http://dx.doi.org/10.1038/eye.2008.36] [PMID: 18344963]

[12] Kang KT, Kim KS, Kim YC. Surgical results of idiopathic and secondary epiretinal membrane. Int Ophthalmol 2014; 34(6): 1227-32. [http://dx.doi.org/10.1007/s10792-014-0010-1] [PMID: 25331229]

[13] Gandorfer A, Haritoglou C, Scheler R, Schumann R, Zhao F, Kampik A. Residual cellular proliferation on the internal limiting membrane in macular pucker surgery. Retina 2012; 32(3): 477-85.

[http://dx.doi.org/10.1097/IAE.0b013e3182246e2a]

[PMID: 22068175]

[14] Koenig SB, Mieler WF, Han DP, Abrams GW. Combined phacoemulsification, pars plana vitrectomy, and posterior chamber intraocular lens insertion. Arch Ophthalmol 1992; 110(8): 1101-4. [http://dx.doi.org/10.1001/archopht.1992.01080200081029] [PMID: 1497524]

[15] Kokame GT, Flynn HW Jr, Blankenship GW. Posterior chamber intraocular lens implantation during diabetic pars plana vitrectomy. Ophthalmology 1989; 96(5): 603-10.

[http://dx.doi.org/10.1016/S0161-6420(89)32842-9] [PMID: 2748116]

[16] Dugas B, Ouled-Moussa R, Lafontaine PO, et al. Idiopathic epiretinal macular membrane and cataract extraction: Combined versus consecutive surgery. Am J Ophthalmol 2010; 149(2): 302-6. [http://dx.doi.org/10.1016/j.ajo.2009.09.011] [PMID: 20103056]

[17] Alexandrakis G, Chaudhry NA, Flynn HW Jr, Murray TG. Combined cataract surgery, intraocular lens insertion, and vitrectomy in eyes with idiopathic epiretinal membrane. Ophthalmic Surg Lasers 1999; 30(4): 327-8. [PMID: 10219044]

[18] Thompson JT. The role of patient age and intraocular gases in cataract progression following vitrectomy for macular holes and epiretinal membranes. Trans Am Ophthalmol Soc 2003; 101: 485-98.

[PMID: 14971590]

[19] Schadlu R, Tehrani S, Shah GK, Prasad AG. Long-term follow-up results of ilm peeling during vitrectomy surgery for premacular fibrosis. Retina 2008; 28(6): 853-7.

[http://dx.doi.org/10.1097/IAE.0b013e3181631962] [PMID: 18536602]

[20] Lee JW, Kim IT. Outcomes of idiopathic macular epiretinal membrane removal with and without internal limiting membrane peeling: A comparative study. Jpn J Ophthalmol 2010; 54(2): 129-34.

[http://dx.doi.org/10.1007/s10384-009-0778-0] [PMID: 20401561]

[21] Pournaras CJ, Emarah A, Petropoulos IK. Idiopathic macular epiretinal membrane surgery and ILM peeling: Anatomical and functional outcomes. Semin Ophthalmol 2011; 26(2): 42-6. [http://dx.doi.org/10.3109/08820538.2010.544237] [PMID: 21469962]

[22] Koutsandrea CN, Apostolopoulos MN, Alonistiotis DA, et al. Indocyanine green-assisted epiretinal membrane peeling evaluated by optical coherence tomography and multifocal electroretinography. Clin Ophthalmol 2007; 1(4): 535-44.

[PMID: 19668533]

[23] Sivalingam A, Eagle RC Jr, Duker JS, et al. Visual prognosis correlated with the presence of internal-limiting membrane in histopathologic specimens obtained from epiretinal membrane surgery. Ophthalmology 1990; 97(11): 1549-52.

[http://dx.doi.org/10.1016/S0161-6420(90)32378-3] [PMID: 2255528]

[24] Oh HN, Lee JE, Kim HW, Yun IH. Clinical outcomes of double staining and additional ILM peeling during ERM surgery. Korean J Ophthalmol 2013; 27(4): 256-60.

[http://dx.doi.org/10.3341/kjo.2013.27.4.256] [PMID: 23908571]

[25] Chang S, Gregory-Roberts EM, Park S, Laud K, Smith SD, Hoang QV. Double peeling during vitrectomy for macular pucker: The Charles L. Schepens Lecture. JAMA Ophthalmol 2013; 131(4): 525-30.

[http://dx.doi.org/10.1001/jamaophthalmol.2013.2176] [PMID: 23579603]

[26] Bovey EH, Uffer S, Achache F. Surgery for epimacular membrane: Impact of retinal internal limiting membrane removal on functional outcome. Retina 2004; 24(5): 728-35.

[http://dx.doi.org/10.1097/00006982-200410000-00007] [PMID: 15492626]

[27] Tranos P, Koukoula S, Charteris DG, et al. The role of internal limiting membrane peeling in epiretinal membrane surgery: A randomised controlled trial. Br J Ophthalmol 2017; 101(6): 719-24. [http://dx.doi.org/10.1136/bjophthalmol-2016-309308] [PMID: 28045374]

[28] Liu H, Zuo S, Ding C, Dai X, Zhu X. Comparison of the effectiveness of pars plana vitrectomy with and without internal limiting membrane peeling for idiopathic retinal membrane removal: A meta-analysis. J Ophthalmol 2015; 2015974568

[http://dx.doi.org/10.1155/2015/974568] [PMID: 26693348]

[29] Niwa T, Terasaki H, Kondo M, Piao CH, Suzuki T, Miyake Y. Function and morphology of macula before and after removal of idiopathic epiretinal membrane. Invest Ophthalmol Vis Sci 2003; 44(4): 1652-6.

[http://dx.doi.org/10.1167/iovs.02-0404] [PMID: 12657605]

[30] Won JY, Kim M, Park YH. Postoperative changes in the retinal thickness and volume after vitrectomy for epiretinal membrane and internal limiting membrane peeling. Medicine (Baltimore) 2017; 96(19)e6709

[http://dx.doi.org/10.1097/MD.0000000000006709]

[PMID: 28489747]

[31] Lee SB, Shin YI, Jo YJ, Kim JY. Longitudinal changes in retinal nerve fiber layer thickness after vitrectomy for epiretinal membrane. Invest Ophthalmol Vis Sci 2014; 55(10): 6607-11.

[http://dx.doi.org/10.1167/iovs.14-14196] [PMID: 25228548]

[32] Mitamura Y, Ohtsuka K. Relationship of dissociated optic nerve fiber layer appearance to internal limiting membrane peeling. Ophthalmology 2005; 112(10): 1766-70.

[http://dx.doi.org/10.1016/j.ophtha.2005.04.026] [PMID: 16095706]

[33] Balducci N, Morara M, Veronese C, Torrazza C, Pichi F, Ciardella AP. Retinal nerve fiber layer thickness modification after internal limiting membrane peeling. Retina 2014; 34(4): 655-63.

[http://dx.doi.org/10.1097/IAE.0000000000000004] [PMID: 24670998]

[34] Kenawy N, Wong D, Stappler T, et al. Does the presence of an epiretinal membrane alter the cleavage plane during internal limiting membrane peeling? Ophthalmology 2010; 117(2): 320-3.e1. [http://dx.doi.org/10.1016/j.ophtha.2009.07.024] [PMID: 20006906]

[35] Terasaki H, Miyake Y, Nomura R, et al. Focal macular ERGs in eyes after removal of macular ILM during macular hole surgery. Invest Ophthalmol Vis Sci 2001; 42(1): 229-34.

[PMID: 11133873]

[36] Robaszkiewicz J, Chmielewska K, Figurska M, Wierzbowska J, Stankiewicz A. Müller glial cells-the mediators of vascular disorders with vitreomacular interface pathology in diabetic maculopathy. Klin Oczna 2010; 112(10-12): 328-32. [PMID: 21469528]

[37] Deltour JB, Grimbert P, Masse H, Lebreton O, Weber M. Detrimental effects of active internal limiting membrane peeling during epiretinal membrane surgery: Microperimetric Analysis. Retina 2017; 37(3): 544-52.

[http://dx.doi.org/10.1097/IAE.0000000000001179]

[PMID: 27429376]

[38] Ito Y, Terasaki H, Takahashi A, Yamakoshi T, Kondo M, Nakamura M. Dissociated optic nerve fiber layer appearance after internal limiting membrane peeling for idiopathic macular holes. Ophthalmology 2005; 112(8): 1415-20.

[http://dx.doi.org/10.1016/j.ophtha.2005.02.023] [PMID: 16061095]

[39] Spaide RF. "Dissociated optic nerve fiber layer appearance" after internal limiting membrane removal is inner retinal dimpling. Retina 2012; 32(9): 1719-26.

[http://dx.doi.org/10.1097/IAE.0b013e3182671191]

[PMID: 23007669]

[40] Ripandelli G, Scarinci F, Piaggi P, et al. Macular pucker: To peel or not to peel the internal limiting membrane? A microperimetric response. Retina 2015; 35(3): 498-507.

[http://dx.doi.org/10.1097/IAE.0000000000000330] 25158943]

[41] Musat O, Stefan C, Boariu AM, et al. Chromovitrectomy. Rom J Ophthalmol 2016; 60(2): 59-62

[PMID: 29450324]

[42] Rodrigues EB, Meyer CH, Schmidt JC, Kroll P. Trypan blue stains the epiretinal membrane but not the internal limiting membrane. $\mathrm{Br} \mathrm{J}$ Ophthalmol 2003; 87(11): 1431-2.

[http://dx.doi.org/10.1136/bjo.87.11.1431-a] [PMID: 14609857]

[43] Meyer CH, Rodrigues EB, Kroll P. Trypan blue has a high affinity to cellular structures such as epiretinal membrane. Am J Ophthalmol 2004; 137(1): 207-8.

[http://dx.doi.org/10.1016/j.ajo.2003.09.014] [PMID: 14700681]

[44] Li K, Wong D, Hiscott P, Stanga P, Groenewald C, McGalliard J. Trypan blue staining of internal limiting membrane and epiretinal membrane during vitrectomy: Visual results and histopathological findings. Br J Ophthalmol 2003; 87(2): 216-9. [http://dx.doi.org/10.1136/bjo.87.2.216] [PMID: 12543755] 
[45] Perrier M, Sébag M. Trypan blue-assisted peeling of the internal limiting membrane during macular hole surgery. Am J Ophthalmol 2003; 135(6): 903-5.

[http://dx.doi.org/10.1016/S0002-9394(02)02239-0] [PMID: 12788140]

[46] Kumar K, Chandnani N, Raj P, Agarwal A. Clinical outcomes of double membrane peeling with or without simultaneous phacoemulsification/gas tamponade for vitreoretinal-interfaceassociated (VRI) disorders. Int Ophthalmol 2016; 36(4): 547-56. [http://dx.doi.org/10.1007/s10792-015-0162-7] [PMID: 26659009]

[47] Hamoudi H, Correll Christensen U, La Cour M. Epiretinal membrane surgery: An analysis of 2-step sequential or combined phacovitrectomy surgery on refraction and macular anatomy in a prospective trial. Acta Ophthalmol 2018; 96(3): 243-50. [http://dx.doi.org/10.1111/aos.13572] [PMID: 28926197]

[48] Chabot G, Bourgault S, Cinq-Mars B, Tourville É, Caissie M. Effect of air and sulfur hexafluoride $\left(\mathrm{SF}_{6}\right)$ tamponade on visual acuity after epiretinal membrane surgery: A pilot study. Can J Ophthalmol 2017; 52(3): 269-72.

[http://dx.doi.org/10.1016/j.jcjo.2016.11.004] [PMID: 28576207]

[49] Emrani E, Matlach J, Guthoff R, Goebel W. Morphologic and functional outcome of epiretinal membrane surgery with and without gas tamponade-a pilot study. Invest Ophthalmol Vis Sci 2014; 55(13): 3829 .

[50] Tachibana T, Yoshida S, Kobayashi Y, et al. Differential improvement of vertical and horizontal metamorphopsia scores after epiretinal membrane vitrectomy with ILM peeling. Acta Ophthalmol 2015; 93(8): e681-2.

[http://dx.doi.org/10.1111/aos.12734] [PMID: 25847725]

51] Yoshikawa M, Murakami T, Nishijima K, et al. Macular migration toward the optic disc after inner limiting membrane peeling for diabetic macular edema. Invest Ophthalmol Vis Sci 2013; 54(1): 629-35.

[http://dx.doi.org/10.1167/iovs.12-10907] [PMID: 23299482]

[52] Kinoshita $T$, Imaizumi $H$, Miyamoto $H$, Katome $T$, Semba $K$, Mitamura Y. Two-year results of metamorphopsia, visual acuity, and optical coherence tomographic parameters after epiretinal membrane surgery. Graefes Arch Clin Exp Ophthalmol 2016; 254(6): 1041-9. [http://dx.doi.org/10.1007/s00417-015-3147-3] [PMID: 26319984]

[53] Kinoshita $T$, Imaizumi $H$, Okushiba $U$, Miyamoto $H$, Ogino $T$, Mitamura Y. Time course of changes in metamorphopsia, visual acuity, and OCT parameters after successful epiretinal membrane surgery. Invest Ophthalmol Vis Sci 2012; 53(7): 3592-7. [http://dx.doi.org/10.1167/iovs.12-9493] [PMID: 22589432]

\section{(C) 2020 Aydin et al.}

This is an open access article distributed under the terms of the Creative Commons Attribution 4.0 International Public License (CC-BY 4.0), a copy of which is available at: (https://creativecommons.org/licenses/by/4.0/legalcode). This license permits unrestricted use, distribution, and reproduction in any medium, provided the original author and source are credited. 